\title{
Effective Biomass Reduction of the Invasive Weed Species Banana Poka by Septoria Leaf Spot
}

\author{
Eduardo E. Trujillo, Professor, Chris Kadooka, Research Associate, Department of Plant Pathology, University \\ of Hawaii, 3190 Maile Way, Honolulu 96822; Victor Tanimoto, Entomologist, Steve Bergfeld, Glenn Shishido, \\ and Galen Kawakami, Foresters, Forestry Protection Section, Division of Forestry and Wildlife, Hawaii Depart- \\ ment of Land and Natural Resources, 1151 Punchbowl St., Honolulu 96813
}

\begin{abstract}
Trujillo, E. E., Kadooka, C., Tanimoto, V., Bergfeld, S., Shishido, G., and Kawakami, G. 2001. Effective biomass reduction of the invasive weed species banana poka by Septoria leaf spot. Plant Dis. 85:357-361.

Inoculations of Septoria passiflorae for biological control of banana poka (Passiflora tripartita var. tripartita) at different forest sites in Hawaii, Kauai, and Maui resulted in successful establishment of the Septoria leaf spot disease at all sites during 1996. Semi-annual monitoring of sites in 1997 revealed low disease incidence and no disease spread to adjacent non-inoculated plants. Site inspections in March 1998 revealed light disease epidemics causing visible defoliation at inoculated sites on Kauai and Maui. Banana poka biomass reduction at sites with light epidemics of the disease in Kauai and Maui were estimated to be less than 10\% in 1998, whereas in 1999 biomass reduction ranged from 50 to $95 \%$. Five of 11 inoculation sites in 1996 on the island of Hawaii showed no disease. These five sites on Kaloko had frequent acid rainfall averaging $3.2 \mathrm{pH}$, which inhibited spore germination and infection. Six sites, free of acid rain, three at Hilo Forest Reserve and three at Puuwaawaa Wildlife Sanctuary, had severe disease epidemics by 1998 , and vine defoliation was $>90 \%$. Widespread epidemics of the disease occurred in 1999, resulting in estimated 80 to $95 \%$ biomass reductions in more than 2,000 hectares of native forest infested with banana poka.
\end{abstract}

Banana poka, Passiflora tripartita (Juss.) Poir var. tripartita Holm-Nie. Jörg. \& LAW. (Passiflora mollissima Neal), is a perennial woody vine of Andean origin (7), which climbs the tallest trees and chokes the forest by reducing sunlight. More than 50,000 hectares are affected in wet and mesic forests of Hawaii, Kauai, and Maui $(4,19)$. Banana poka is a serious threat to native koa $(8,9)$ and to the survival of approximately 20 endangered Hawaiian plant species (5). Since 1983, the Hawaii Department of Land and Natural Resources, Division of Forestry and Wildlife, has funded biological control research to stop the spread of this weed. Two lepidopterous species released in 1989 and $1991(1,6)$ failed to become established. The highly specific flower-abortive fly Zapriothrica sp., which was reported in 1996 (2), is undergoing extensive host range studies in Hawaii to satisfy environmental concerns

Corresponding author: Eduardo E. Trujillo E-mail: trujillo@hawaii.edu

Accepted for publication 12 December 2000.

Publication no. D-2001-0122-03R

(C) 2001 The American Phytopathological Society of United State Department of the Interior Fish and Wildlife Service. Many fungal pathogens were observed on high-elevation Passifloraceae during exploration trips to the Andean region of Colombia and Ecuador in 1983 to 1984 . Most of the fungi were pathogenic to curuba ( $P$. tripartita var. mollissima) but not to banana poka $(P$. tripartita var. tripartita). Only two pathogens were found on banana poka. The first, Phyllactinia sp. was discovered on banana poka in 1987 at Providencia near Pasto, Nariño, Colombia. Although this powdery mildew fungus was highly specific to banana poka, it did not survive air transportation from Colombia to Hawaii. The second pathogen, Septoria passiflorae Syd. was discovered in 1991 at Aldana near Ipiales, Nariño, Colombia. This fungus was readily transported to Hawaii in airdried diseased banana poka leaves.

Host range studies with $S$. passiflorae conducted in 1993 and 1994 at the Hawaii Department of Agriculture Quarantine Laboratory confirmed its specificity to the banana poka vine (10). On 30 March 1995 the Hawaii Board of Agriculture approved its release as a biological control agent of this weed. Hawaii's permit to release this pathogen was reviewed by USDA-APHIS, and after completion of an Environmental
Assessment, approval was granted under USDA Permit 952171 on 23 February 1996. Pathogen release began in March 1996 on Kauai, in April on Hawaii, and in July on Maui. The effect of $S$. passiflorae as a biological control agent of the invasive banana poka and the significant biomass reduction caused by this pathogen in forest of Hawaii is reported here.

\section{MATERIALS AND METHODS}

Inoculum produced in 1995 and stored in kaolin was used for formulation of bioherbicide sprays (7). The viability of the active ingredient used was rated at $87 \%$. This was done by microscopic observation of spore germination on potato dextrose agar in 20- $\mu$ l samples of 7-fold dilution of the active ingredient stored more than 1 year at $10^{\circ} \mathrm{C}(7)$. The concentration of viable spores (cfu) was approximately 1.2 $\times 10^{8} / \mathrm{g}$ of clay. Banana poka vines were sprayed with $5 \times 10^{5} \mathrm{cfu} / \mathrm{L}$ of distilled water with $0.5 \%$ gelatin and $2 \%$ sucrose. Vines were sprayed with a hand-held 32-oz plastic bottle sprayer (Spryco, Detroit). Spray was directed to the underside of the foliage to avoid spores being washed off by rain and was applied to vines from 1 to $2 \mathrm{~m}$ from the surface of the forest floor.

The reference marker-photopoint system of Case et al. (3) was used to identify and monitor test sites. Color photographs of test sites were taken at the time of inoculation. Each selected site was rated at $100 \%$ biomass of the weed before inoculations. Photographs of the sites taken on subsequent visits were visually compared to the initial photo of each photopoint site and the reduction of weed biomass was visually estimated. Originally, S. passiflorae was inoculated in early 1996 at banana poka infested forest sites of Kauai, Hawaii, and Maui. Spore suspensions were applied on 19 March, 1 May, 3 July, and 31 July 1996 at seven sites from 1,050 to $1,140 \mathrm{~m}$ elevation at Kokee State Park, Kauai. Inoculations at Kula Forest Reserve, Maui were done on 12 July and 22 August at seven sites from 1,070 to $1,205 \mathrm{~m}$ elevation. Hawaii island inoculation were done 12 July and 23 August at Kaloko Mauka in Kona at 1,100, 1,190, 1,270, 1,320, and 
1,450 m elevations; at the Hilo Forest Reserve at $1,600,1,800$, and $1,830 \mathrm{~m}$ elevations. The Puuwaawaa Wildlife Sanctuary was inoculated at 1,390, 1,520, and 1,580 m elevations on 6 August.

After fungus inoculation monthly monitoring was conducted to determine disease presence on inoculated vines for a 6-month period. Thereafter, monitoring was done every 6 months to determine disease progress and degree of banana poka biomass reduction. Microscopic examination of lesions for the presence of pycnidia and spores of the pathogen confirmed the disease's presence. Lesion counts were made from diseased leaf samples collected from Kokee sites and compared to lesion counts of non-inoculated leaves from adjacent vines. A random block design was used in field tests. Data were analyzed by one-way analysis of

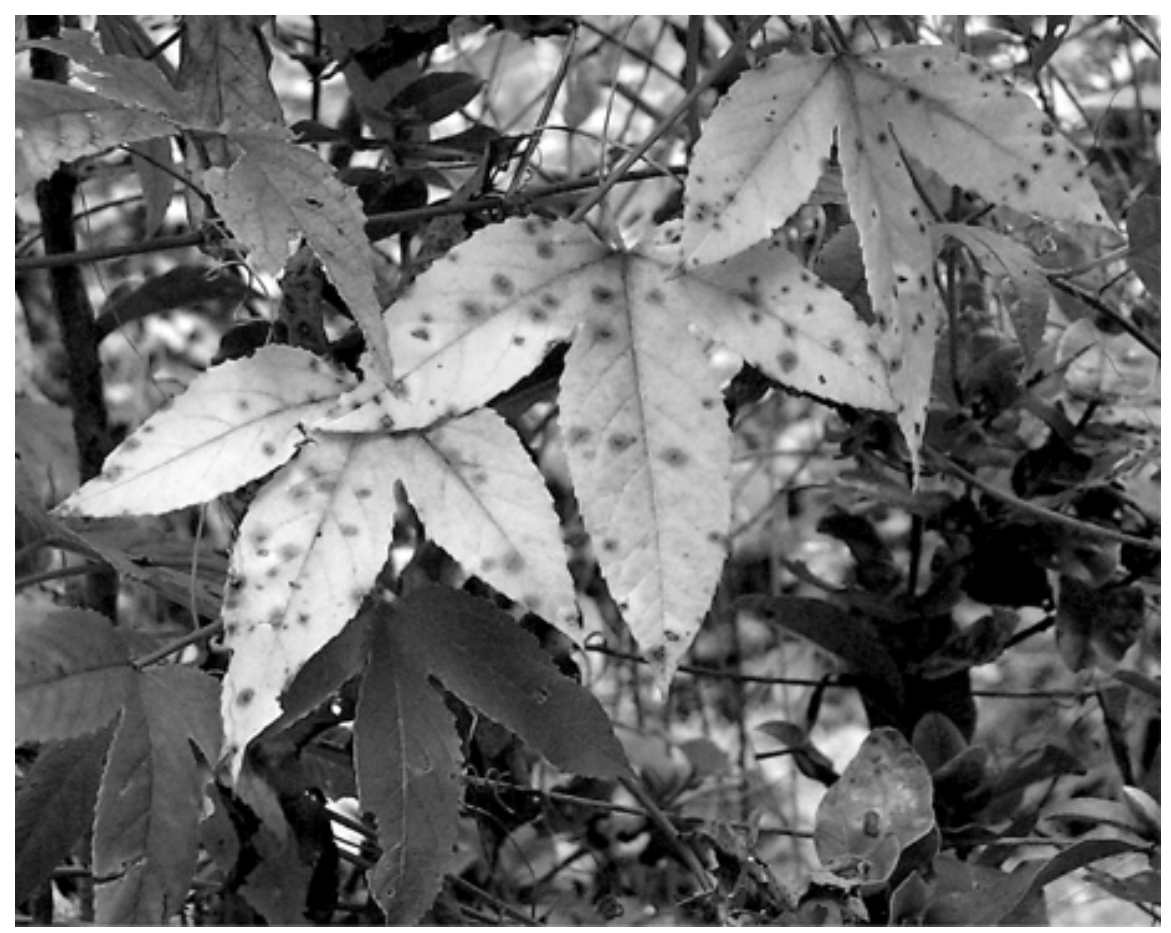

Fig. 1. Symptoms of Septoria passiflorae leaf spot on banana poka leaves 3 weeks after field inoculation at Kokee, Kauai. Leaves became chlorotic, and a green halo developed around the necrotic spots prior to leaf abscission.

Table 1. Number of Septoria passiflorae leaf spots developing on leaves of field inoculated banana poka vines 1 month after inoculation at three sites from 1,050 to 1,140 m in Kokee, Kauai ${ }^{\mathrm{y}}$

\begin{tabular}{|c|c|c|c|c|c|c|}
\hline \multirow{2}{*}{$\begin{array}{l}\text { Leaf } \\
\text { number }\end{array}$} & \multicolumn{2}{|c|}{ Site $1(1,050 \mathrm{~m})$} & \multicolumn{2}{|c|}{ Site $2(1,100 \mathrm{~m})$} & \multicolumn{2}{|c|}{ Site $3(1,140 \mathrm{~m})$} \\
\hline & Inoculated & Not inoculated & $\overline{\text { Inoculated }}$ & Not inoculated & $\overline{\text { Inoculated }}$ & Not inoculated \\
\hline 1 & 257 & 0 & 50 & 0 & 79 & 0 \\
\hline 2 & 102 & 0 & 38 & 0 & 23 & 0 \\
\hline 3 & 141 & 0 & 171 & 0 & 159 & 0 \\
\hline 4 & 58 & 0 & 33 & 0 & 50 & 0 \\
\hline 5 & 10 & 0 & 37 & 0 & 53 & 0 \\
\hline 6 & 8 & 0 & 24 & 0 & 19 & 0 \\
\hline $\operatorname{Mean}^{\mathrm{z}}$ & $95.7 \mathrm{a}$ & $0 \mathrm{~b}$ & $58.8 \mathrm{a}$ & $0 \mathrm{~b}$ & $63.8 \mathrm{a}$ & $0 \mathrm{~b}$ \\
\hline
\end{tabular}

${ }^{y}$ Spore suspensions containing $5 \times 10^{5} \mathrm{CFU} / \mathrm{L}$ of $S$. passiflorae in $0.5 \%$ gelatin, $2 \%$ sucrose distilled water were used for field inoculations.

${ }^{z}$ Means in rows with same letter are not significantly different, $P \leq 0.05$ (Tukey's honestly significant difference). made 1 month after inoculation from sets of six diseased banana poka leaves collected arbitrarily from three different sites at Kokee showed a wide range in the number of Septoria leaf spots. Lesion counts were from 8 to 257 lesions per leaf on inoculated vines whereas leaves from uninoculated vines were free of the disease (Table 1). Similar numbers of Septoria lesions resulted from banana poka inoculations at other forest sites at Maui and Hawaii (Tables 2 and 3 ).

Septoria leaf spot at Kokee Forest, Kauai. Members of a Kauai basket weaver club inadvertently harvested the inoculated banana poka vines from five sites at Kokee, Kauai before the second monthly disease assessment could be done. Monitoring of the two remaining sites 2 months after inoculations, however, confirmed spread of the pathogen within the vines at Kokee. Pathogen-spread to adjacent healthy vines did not occur in 1996 from inoculated vines showing leaf spots. Diseased leaves became bright yellow, senesced and dropped to the forest floor. Inoculations of juvenile plants produced symptoms on leaves, young succulent tendrils, and lateral vines, causing defoliation and death of the infected plant in 2 to 3 months. In 1996, 1997, and 1999 severe drought conditions occurred at Kokee, and disease did not develop. The average monthly precipitation at the Mohihi UPR Cross station, Kokee, Kauai, from July to December 1996 was $7 \mathrm{~cm}$ (12), and from June to October 1997, $8.2 \mathrm{~cm}$ (13). Low incidence of the disease occurred from January through March 1998, and adjacent banana poka became diseased. Average monthly rainfall for July to December 1998 was $9.1 \mathrm{~cm}$ (14). A biomass reduction of 20 to $30 \%$ was recorded for this period, and by December 1999 banana poka biomass had decreased by more than $50 \%$. Although for February to May there was no precipitation in 1999 the average monthly rainfall for June to December 1999 was $10.3 \mathrm{~cm}$ (15).

Inoculations at Kula Forest Reserve, Maui. Establishment of Septoria leaf spot at the high elevation forests of Maui was delayed by environmental factors that were not favorable for severe epidemics in 1996, 1997, and 1998. The weather recording station Ulupalakua Ranch in Maui, $5 \mathrm{~km}$ from the inoculation sites, had $3.36 \mathrm{~cm}$ average monthly rainfall for July to October 1996 (12), $5.7 \mathrm{~cm}$ for May to December 1997 (13), and $2.3 \mathrm{~cm}$ for the year 1988 (14). In a normal year monthly precipitation for Upalakua Ranch approximates $8 \mathrm{~cm}$. In early 1999, after a 3-month period of cool, overcast, and foggy weather, epidemics were severe and the forest floor under diseased vines at 1,070 to $1,205 \mathrm{~m}$ elevation was littered with diseased banana poka leaves. The banana poka biomass reduction was estimated at $>95 \%$ on July 1999 which was also a dry 
year Upalakua Ranch (15). Apparently monthly precipitation at inoculated banana poka sites in Maui could have been higher than those at the Upalakua Ranch, but no records are available for these sites.

Inoculations at Kaloko Mauka-Kona, Hilo Forest Reserve, and Puuwaawaa Wildlife Sanctuary, Hawaii. Semi-annual monitoring at Kaloko Mauka-Kona showed the presence of the pathogen on banana poka leaves at the $1,320 \mathrm{~m}$ site. S. passiflorae, lesions on infected leaves at this site had few pycnidia and the incidence of disease was low with $<10$ lesions per inoculated leaf. Although the pathogen had produced characteristic symptoms 1 month after inoculation at all sites, no disease was recorded at 1,100,1,190,1,270, and 1,450 $\mathrm{m}$ sites 6 months or 1 year after inoculation. The failure of the pathogen to incite disease epidemics at Kaloko was attributed to the deleterious effect of acid rain due to sulfur dioxide released to the atmosphere at an average of $2,000 \mathrm{mt}$ daily by Kilauea volcano (11). Rainwater $\mathrm{pH}$ values (Trujillo, unpublished data) at five catchment sites of Palani cattle ranch in Kona ranged from 3.1 to 3.3. Spore germination was inhibited by $\mathrm{pH} 3.2$ of sterile distilled water in laboratory tests (Trujillo, unpublished data).

Inoculations during July and August 1996 at Hilo Forest Reserve at 1,600, 1,800 , and $1,850 \mathrm{~m}$ elevations and at Puuwaawaa Wildlife Sanctuary at 1,390,
1,520 , and 1,580 $\mathrm{m}$ elevations resulted in disease epidemics a year after inoculations. Average monthly rainfall for Keanakolu camp weather station was $19.28 \mathrm{~cm}$ in 1997 (16), $11.72 \mathrm{~cm}$ in 1998 (17), and $19.62 \mathrm{~cm}$ in 1999 (18). Banana poka vine defoliation at the 3 sites in the Hilo forest was 40 to $70 \%$ by June 1998 . The defoliation due to the disease in 1999 was easily observed and quantified in the reference marker-photopoint photographs (Figs. 2 and 3). Weed-biomass reduction was $>95 \%$ 4 years after inoculation at all reference marker-photopoint sites monitored in the Hilo Forest Reserve. The Puuwaawaa sites showed similar disease severity, with pathogen distribution reaching widespread proportions 2 years after inoculation. This pathogen not only causes severe defoliation of the vines, it invades succulent lateral vines and tendrils to kill the vines. It is estimated that fruit production at Hilo Forest Reserve has decreased by $>90 \%$ in the last 4 years.

Further monitoring of these sites by helicopter in 1999 confirmed widespread epidemics of the disease in more than 5,000 hectares of Hilo Forest Reserve and more than 300 hectares of Puuwaawaa Wildlife Sanctuary. Apparently inoculum was readily airborne as diseased vines were found more than $2.5 \mathrm{~km}$ from the initial inoculation sites in the opposite direction to the trade wind. The rapid distribution of $S$. passiflorae within banana

Table 2. Number of Septoria passiflorae leaf spots developing on leaves of field-inoculated banana poka vines 1 month after inoculation at three sites from 1,070 to 1,090 m in Kokee, Kauai ${ }^{y}$

\begin{tabular}{|c|c|c|c|c|c|c|}
\hline \multirow{2}{*}{$\begin{array}{l}\text { Leaf } \\
\text { number }\end{array}$} & \multicolumn{2}{|c|}{ Site $1(1,070 \mathrm{~m})$} & \multicolumn{2}{|c|}{ Site $2(1,080 \mathrm{~m})$} & \multicolumn{2}{|c|}{ Site $3(1,090 \mathrm{~m})$} \\
\hline & Inoculated & Not inoculated & Inoculated & Not inoculated & Inoculated & Not inoculated \\
\hline 1 & 30 & 0 & 44 & 0 & 7 & 0 \\
\hline 2 & 18 & 0 & 38 & 0 & 57 & 0 \\
\hline 3 & 141 & 0 & 92 & 0 & 25 & 0 \\
\hline 4 & 5 & 0 & 51 & 0 & 27 & 0 \\
\hline 5 & 67 & 0 & 49 & 0 & 24 & 0 \\
\hline 6 & 50 & 0 & 28 & 0 & 125 & 0 \\
\hline $\operatorname{Mean}^{z}$ & $56.9 \mathrm{a}$ & $0 \mathrm{~b}$ & $50.3 \mathrm{a}$ & $0 \mathrm{~b}$ & $40.2 \mathrm{a}$ & $0 \mathrm{~b}$ \\
\hline
\end{tabular}

${ }^{\text {y }}$ Spore suspensions containing $5 \times 10^{5} \mathrm{CFU} / \mathrm{L}$ of $S$. passiflorae in $0.5 \%$ gelatin, $2 \%$ sucrose distilled water were used for field inoculations.

${ }^{\mathrm{z}}$ Means in rows with same letter are not significantly different, $P \leq 0.05$ (Tukey's honestly significant difference).

Table 3. Number of Septoria passiflorae leaf spots developing on leaves of field-inoculated banana poka vines 1 month after inoculation at three sites from 1,600 to 1,850 m at Kealakolo, Hilo Forest Reserve, Hawaii ${ }^{\mathrm{y}}$

\begin{tabular}{|c|c|c|c|c|c|c|}
\hline \multirow{2}{*}{$\begin{array}{l}\text { Leaf } \\
\text { number }\end{array}$} & \multicolumn{2}{|c|}{ Site $1(1,600 \mathrm{~m})$} & \multicolumn{2}{|c|}{ Site $2(1,800 \mathrm{~m})$} & \multicolumn{2}{|c|}{ Site $3(1,850 \mathrm{~m})$} \\
\hline & Inoculated & Not inoculated & Inoculated & Not inoculated & $\overline{\text { Inoculated }}$ & Not inoculated \\
\hline$\overline{1}$ & 134 & 0 & 89 & 0 & 109 & 0 \\
\hline 2 & 84 & 0 & 45 & 0 & 27 & 0 \\
\hline 3 & 75 & 0 & 211 & 0 & 190 & 0 \\
\hline 4 & 74 & 0 & 45 & 0 & 53 & 0 \\
\hline 5 & 77 & 0 & 67 & 0 & 39 & 0 \\
\hline 6 & 234 & 0 & 11 & 0 & 99 & 0 \\
\hline $\operatorname{Mean}^{z}$ & $130.0 \mathrm{a}$ & $0 \mathrm{~b}$ & $78.0 \mathrm{a}$ & $0 \mathrm{~b}$ & $86.2 \mathrm{a}$ & $0 \mathrm{~b}$ \\
\hline
\end{tabular}

${ }^{y}$ Spore suspensions containing $5 \times 10^{5} \mathrm{CFU} / \mathrm{L}$ of $S$. passiflorae in $0.5 \%$ gelatin, $2 \%$ sucrose distilled water were used for field inoculations.

${ }^{\mathrm{z}}$ Means in rows with same letter are not significantly different, $P \leq 0.05$ (Tukey's honestly significant difference). poka infestation of wet mesic koa/ohia forest of Hawaii precludes the commercialization of this pathogen as a mycoherbicide. Re-inoculations of host sites were not required as is characteristic of classical biological control (10).

The canopy of the native Acacia koa Gray trees 25 to $30 \mathrm{~m}$ high that were covered and shaded by the weed before inoculation (8) is open to sunlight. Debilitated trees are showing renewed vigor by producing new foliage. The impact of this pathogen on the survival of

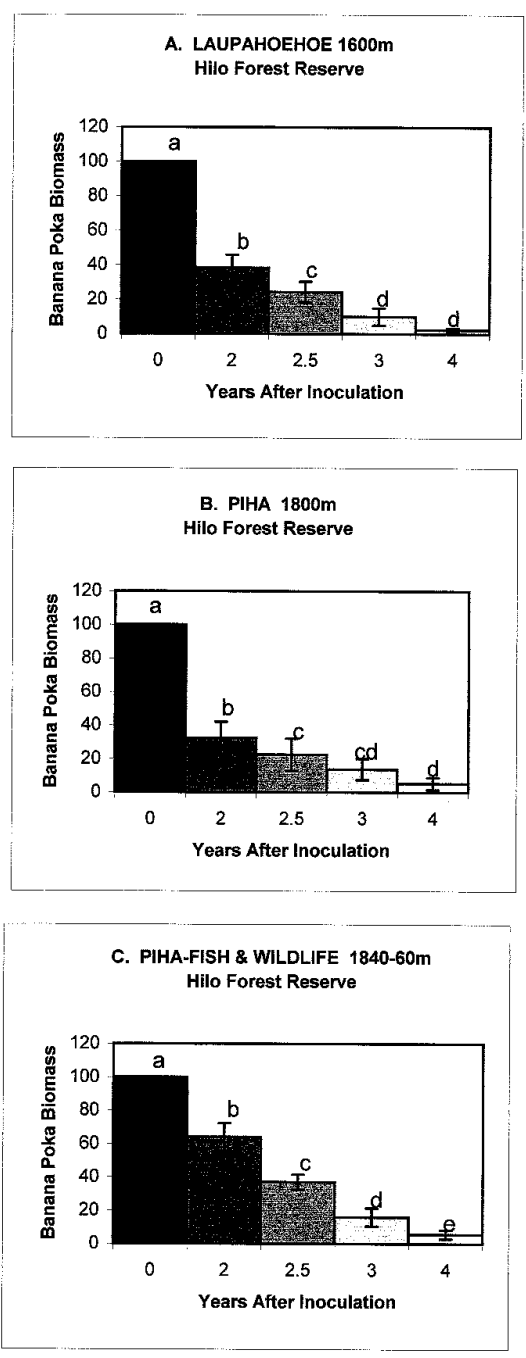

Fig. 2. Banana poka biomass reduction caused by Septoria passiflorae, at A, Laupahoehoe; $\mathbf{B}$, Piha; and $\mathbf{C}$, Piha-Fish and Wildlife reference marker-photopoints sites at Kealakolo road, Hilo Forest Reserve. Each bar at sites A, B, and $\mathrm{C}$ represents data from 3,5 , and 5 reference marker-photopoints, respectively. Pictures taken before inoculation (time 0) were estimated at $100 \%$ banana poka biomass. Subsequent photographs taken every 6 months were compared to photographs before inoculation and biomass reduction visually quantified. Banana poka biomass reduction means with different letters in years after inoculation are significantly different, $P \leq 0.05$ (Tukey's honestly significant difference). 

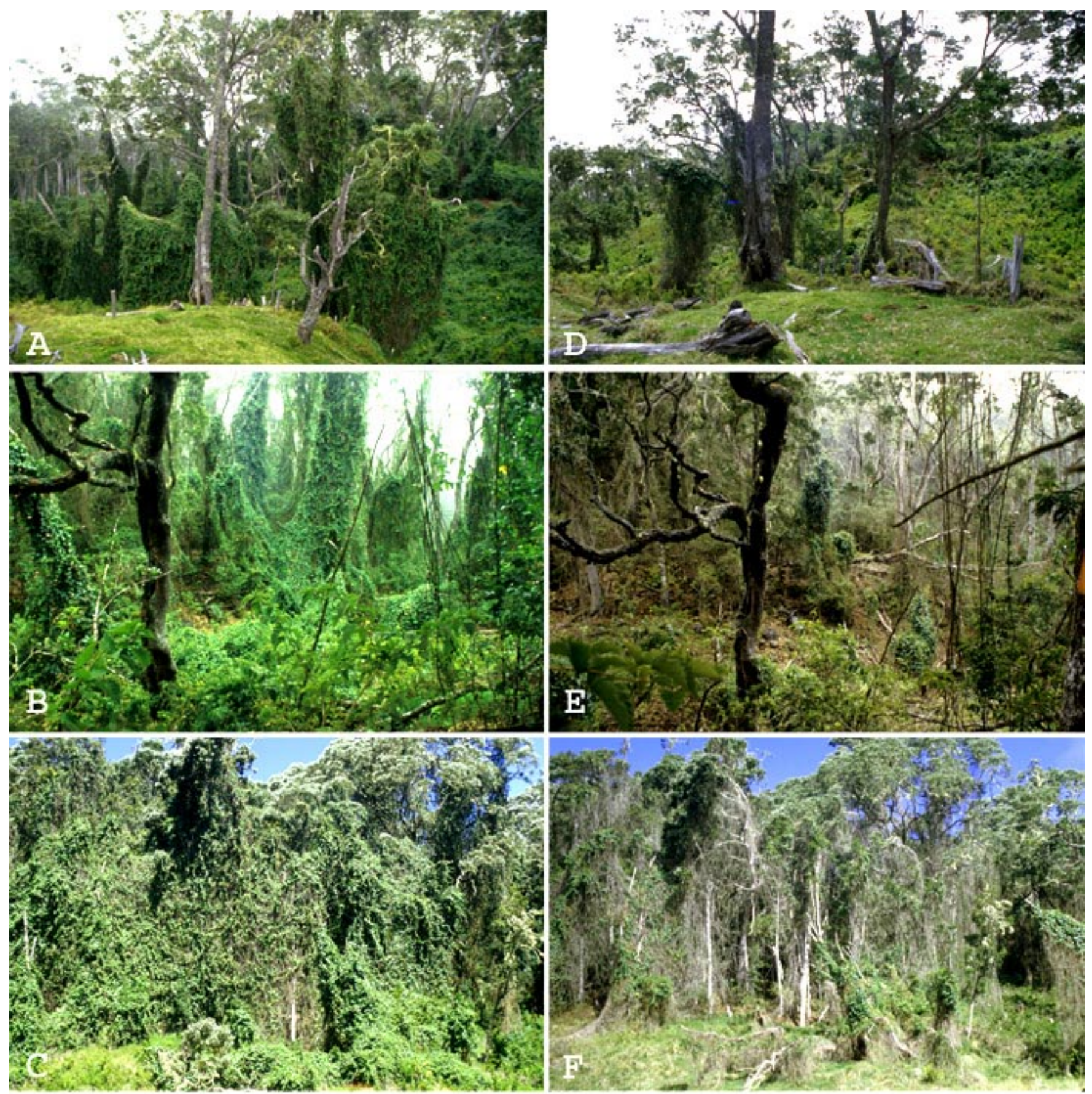

Fig. 3. Effect of Septoria passiflorae on banana poka biomass reduction from 1996 to 2000 at Hilo Forest Reserve, island of Hawaii. Three banana poka infestations photographed in 1996 before release of the biocontrol fungus: A, Laupahoehoe-photopoint, 1,600 m; B, Piha-photopoint 4, 1,800 m; and C, Piha road bordering USDI-Fish and Wildlife Preserve-photopoint 2, 1,850 m. Notice the vigorous growth of banana poka vines climbing to the top of native Koa trees on C. Photographs of the three sites 4 years later showing $>95 \%$ banana poka biomass reduction: D, Laupahoehoe-photopoint; E, Pihaphotopoint 4; and F, Piha road bordering USDC-Fish and Wildlife Preserve-photopoint 2.

endangered Hawaiian plant species appears to be highly significant. It is predicted that this pathogen will reduce banana poka infestation to insignificant levels in time, assuring the continuous survival of threatened species $(4,5)$ and contributing to the re-establishment of healthy koa in Hawaii (9).

\section{ACKNOWLEDGMENTS}

This work was funded partially by the State of Hawaii, Department of Land and Natural Resources and U. S. Department of Agriculture,
Forest Service Pacific Southwest Research Station. Journal Series 4527. Hawaii College of Tropical Agriculture and Human Resources.

\section{LITERATURE CITED}

1. Campbell, C. L., Markin, G. P., and Johnson, M. J. 1995. Fate of Cyanotricha necyria (Lepidoptera: Notodontidae) and Pyrausta perelegans (Lepidoptera: Pyralidae) released for biological control of banana poka (Passiflora mollissima) on the island of Hawaii. Proc. Hawaii. Entomolog. Soc. 1991-93. 32:123-130

2. Casanas-Arango, A. D., Trujillo, E. E., Friesen, R. D., and Hernandez, M. R. de. 1996.
Field biology of Zapriothrica sp. Wheeler (Dip., Drosophilidae) a pest of Passiflora spp. of high elevation possessing long tubular flowers. J. Appl. Ent. 120:111-114.

3. Case, J. L., Toops, P. L., and Shabica, S. V. 1982. Reference marker-photopoint resources management system. US Dep. Int. Natl. Park Serv. Rep. 62.

4. Cuddihy, L. W., and Stone, C. P. 1990. Alteration of Native Hawaiian Vegetation Effects of Humans, Their Activities and Introductions. Honolulu. University of Hawaii Press.

5. Jacobi, J. D., and Scott, J. M. 1985. An assessment of the current status of native upland 
habitats and associated endangered species on the island of Hawaii. Pages 3-22 in 1., Hawaii's Terrestrial Ecosystems Preservation and Management. C. P. Stone and J. M. Scott, eds. Coop. Nat. Park Resour. Stud. Unit Univ. Hawaii, Honolulu.

6. Markin, G. P., Nagata, R. F., and Taniguchi, G. 1989. Biology and behavior of the South American moth, Cyanotricha necyria (Felde and Rogenhofer) (Lep., Notodontidae), a potential biocontrol agent in Hawaii of the forest weed Passiflora mollissima (Hbk) Bailey. Proc. Hawaii. Entomol. Soc. 29:115-123.

7. Norman, D. J., and Trujillo, E. E. 1995. Development of Colletotrichum gloeosporioides f.sp. clidemiae and Septoria passiflorae into two mycoherbicides with extended viability. Plant Dis. 79:1029-1032.

8. Muller-Dombois, D. 1975. Some aspects of island ecosystem analysis. Pages 353-366 in
Tropical Ecological Systems Trends in Terrestrial and Aquatic Research. F. B. Golley and E. Medina, eds. Springer-Verlag New York.

9. Scowcroft, P. G., and Nelson, R. E. 1976. Disturbance during logging stimulates regeneration of koa: USDA Forest Serv. Res. Note PSW-306. Pac. SW Forest Range Exp. Sta. Berkeley, CA.

10. Trujillo, E. E. 1992. Bioherbicides. Pages 196-211 in Frontiers in Industrial Mycology. G. F. Leatham, ed. Champman and Hall, New York.

11. Trujillo, E. E., Norman, D. J., and Killgore, E. M. 1994. Septoria leaf spot, a potential biological control for banana poka vine in forests of Hawaii. Plant Dis. 78:883-885.

12. U.S. Geological Survey. 2000. Volcanic air pollution: A hazard in Hawai'i. USGS Fact Sheet 169-97, Online version 1.1.
13. U.S. Dep. Comm. 1996. Climatologial Data Annual Summary: Hawaii and Pacific 92:13.

14. U.S. Dep. Comm. 1997. Climatological Dat Annual Summary: Hawaii and Pacific 93:13.

15. U.S. Dep. Comm. 1998. Climatologial Data Annual Summary: Hawaii and Pacific 94:13.

16. U.S. Dep. Comm. 1999. Climatological Data Annual Summary: Hawaii and Pacific 95:13.

17. U.S. Dep. Comm. 1997. Hourly Precipitation Data. Hawaii: Alaska and Pacific 33:12.

18. U.S. Dep. Comm. 1998. Hourly Precipitation Data. Hawaii: Alaska and Pacific 34:12.

19. U.S. Dep. Comm. 1999. Hourly Precipitation Data. Hawaii: Alaska and Pacific 35:12.

20. Warshauer, F. R., Jacobi, J. D., La Rosa, A. M., Scott, J. M., and Smith, C. W. 1983. The distribution, impact, and potential management of the introduced vine Passiflora mollissima (Passifloraceae) in Hawaii. Univ. Hawaii Tech. Rep. 48. 